\title{
Curcumin, demethoxycurcumin, and bisdemethoxycurcumin induced caspase- dependent and -independent apoptosis via Smad or Akt signaling pathways in HOS cells
}

\author{
Cheng Huang ${ }^{1,2+}$ (D), Hsu-Feng Lu ${ }^{3,4+}$, Yu-Hsuan Chen ${ }^{5}$, Jui-Chieh Chen ${ }^{6}$, Wen-Hsiang Chou ${ }^{7,8}$ and \\ Hsiu-Chen Huang ${ }^{5^{*}}$
}

\begin{abstract}
Background: Osteosarcoma is the most common primary malignant bone tumor in children and adolescents and has also been associated with a high degree of malignancy and enhanced metastatic capacity. Curcumin (CUR) is well known for its anti-osteosarcoma activity. However, both demethoxycurcumin (DMC), and bisdemethoxycurcumin (BDMC) are natural curcumin analogues/congeners from turmeric whose role in osteosarcoma development remains unknown.

Methods: To evaluate the growth inhibitory effects of CUR, DMC and BDMC on osteosarcoma (HOS and U2OS), breast (MDA-MB-231), and melanoma (A2058) cancer cells, we employed the MTT assay, annexin V-FITC /7-AAD staining, and clonogenic assay.

Results: CUR,DMC, and BDMC all decreased the viability of HOS, U2OS, MDA-MB-231, and A2058 cancer cells. Additionally, CUR,DMC, and BDMC induced the apoptosis of HOS cells through activation of Smad 2/3 or repression of Akt signaling pathway. Furthermore, the combination of CUR,DMC, and BDMC synergistically reduced cell viability, colony formation and increased apoptosis than either two or a single agent in HOS cells.

Conclusions: The combination of these three compounds could be used as a novel target for the treatment of osteosarcoma.
\end{abstract}

Keywords: Curcumin, Demethoxycurcumin, Bisdemethoxycurcumin, Apoptosis, Osteosarcoma

\section{Background}

Turmeric is a yellow Indian spice obtained from the rhizome of Curcuma longa Linn which is a type of herb belonging to Zingiberaceae family. The three major

\footnotetext{
* Correspondence: jane@mail.nd.nthu.edu.tw

${ }^{+}$Cheng Huang and Hsu-Feng Lu contributed equally to this work. ${ }^{5}$ Department of Applied Science, National Tsing Hua University South Campus, No.521, Nanda Rd, Hsinchu City 30014, Taiwan

Full list of author information is available at the end of the article
}

chemical constituents and biological activities of turmeric were approximately 77\% curcumin (CUR), 17\% demethoxycurcumin (DMC), and 3\% bisdemethoxycurcumin (BDMC), which are belong to curcuminoids $[1,2]$. Cur, a linear diarylheptanoid, is a natural phenolic compound and it has been well known and used to treat many diseases, such as cancer [3-6], diabetes [7, 8], inflammation [1] and neurodegenerative disorders $[9,10]$. In spite of the potential health benefits of CUR, its clinical applications

(c) The Author(s). 2020 Open Access This article is licensed under a Creative Commons Attribution 4.0 International License, which permits use, sharing, adaptation, distribution and reproduction in any medium or format, as long as you give appropriate credit to the original author(s) and the source, provide a link to the Creative Commons licence, and indicate if changes were made. The images or other third party material in this article are included in the article's Creative Commons licence, unless indicated otherwise in a credit line to the material. If material is not included in the article's Creative Commons licence and your intended use is not permitted by statutory regulation or exceeds the permitted use, you will need to obtain permission directly from the copyright holder. To view a copy of this licence, visit http://creativecommons.org/licenses/by/4.0/ The Creative Commons Public Domain Dedication waiver (http://creativecommons.org/publicdomain/zero/1.0/) applies to the data made available in this article, unless otherwise stated in a credit line to the data. 
are limited due to its low oral bioavailability, low water solubility, and instability at acidic Ph $[11,12]$. DMC and BDMC are naturally occurring CUR analogues, which lacks one or two methoxy groups on the aromatic rings of CUR [13]. DMC and BDMC exhibited much better chemical stability than CUR and both have been recently reported to exhibit anticancer properties [14]. Until now, the detailed mechanisms of DMC and BDMC in cancer prevention are still mostly unknown, and these two compounds must remain to be investigated.

Osteosarcoma is one of the most common primary malignant bone tumor originating from mesenchymal stem cells, and it occurred predominantly in late childhood and early adolescence [15]. Chemotherapy in treating nonmetastatic osteosarcoma patients has dramatically improved the five-year survival rates from $<20$ to $60 \%-70 \%$ [16-18]. While osteosarcoma is not very sensitive to chemotherapy $[19,20]$. Thus, it is difficult to develop more effective treatments. Recently, curcuminoids have been increasingly used for the treatment of osteosarcoma to overcome chemoresistance and increased the apoptotic rate of osteosarcoma cells [21]. Apoptosis, or programmed cell death (PCD), is a regulated cellular suicide and the inducing apoptosis plays a critical role in the development of new anticancer drugs [22]. CUR, the principal curcuminoid of turmeric, has also been reported to induce apoptosis in various cancer cells, and have the potential for being developed as cancer therapeutic agents. Although CUR also has shown to induce cell death and cell cycle arrest in HOS cells, the mechanism has not been fully established [23]. Whether analogs of CUR, such as DMC and BDMC also could regulate osteosarcoma cell proliferation to a similar extent as CUR and the mechanisms remain to be investigated. To our knowledge, this is the first time study to identify the anti-cancer effects of DMC and BDMC on osteosarcoma cells. Thus, we will investigate the effects of CUR, DMC and BDMC on cell proliferation in osteosarcoma (HOS and U2OS), breast (MDA-MB231), and melanoma (A2058) cancer cells in the present study.

\section{Methods}

\section{Chemicals}

Curcumin (CAS Number 458-37-7, Sigma-Aldrich, Purity: $\geqq 99.5 \%$ ), demethoxycurcumin (CAS Number: 2260811-3, Sigma-Aldrich, Purity: $\geqq 98 \%$ ), bisdemethoxycurcumin (CAS Number: 33171-05-0, Sigma-Aldrich, Purity: $\geqq 98 \%$ ), Thiazolyl Blue Tetrazolium Bromide (MTT) were purchased from Sigma-Aldrich (CAS Number: 298-931). $\beta$-actin (Cat No. GTX109639), p-p38 (Cat No. GTX24822), p-Akt (Cat No. GTX128414), p-Erk (Cat No. GTX24819), p-smad2 (Cat No. GTX133475), p- smad3 (Cat No. GTX129841), cleaved PARP (Cat No. GTX132329), cleaved caspase 3 (Cat No. GTX86952) antibodies were purchased from GeneTex. Annexin V Alexa Fluor 488 Ready Flow Conjugate (Lot number 2081235) and 7-aminoactinomycin D (7-AAD, Catalog number: A1310) both were purchased from Thermo Fisher Scientific.

\section{Cell line and cell culture}

The U2OS, HOS, A2058, MDA-MB-231 cell lines were obtained from Bioresource Collection and Research Center (BCRC, Hsinchu, Taiwan). Cells in culture were not more than 10 passages from the time of receipt. Cells were cultured in Dulbecco's Modified Eagle's Medium (DMEM) supplemented with antibiotics (100 $\mathrm{U} / \mathrm{mL}$ of penicillin $\mathrm{A}$ and $100 \mathrm{U} / \mathrm{mL}$ of streptomycin) and $10 \%$ fetal bovine serum (FBS), and maintained at $37^{\circ} \mathrm{C}$ in $5 \% \mathrm{CO}_{2}$ humidified air.

\section{Cell viability assay}

The effect of CUR, DMC and BDMC on cell viability in U2OS, HOS, A2058, and MDA-MB-231 cells were examined by MTT assay. Briefly, cells were seeded into 12well plates with $10 \%$ FBS overnight. After attachment, the cells were put into $2 \%$ FBS media and then treated with varying concentrations of CUR, DMC and BDMC alone or in combination. After incubation for 24-48 h, $300 \mu \mathrm{L}$ of MTT working solution $(0.5 \mathrm{mg} / \mathrm{mL})$ was added to each well and incubated for $3 \mathrm{~h}$ at $37^{\circ} \mathrm{C}$. The supernatant was aspirated, and the MTT-formazan crystals formed by metabolically viable cells were dissolved in DMSO. Finally, the absorbance was monitored by a 96well microplate reader at a wavelength of $540 \mathrm{~nm}$.

\section{Flow cytometric analysis of apoptosis}

HOS cells were cultured at a density of $1 \times 10^{6}$ cells in $10-\mathrm{cm}$ dishes with $10 \%$ FBS overnight. After attachment, the cells were put into $2 \%$ FBS media and then treated with varying concentrations of CUR, DMC and BDMC alone or in combination. After treatment with varying concentrations of CUR, DMC and BDMC for $24 \mathrm{~h}$, we collected the cell pellet by trypsinization and centrifugation at $2000 \mathrm{~g}$ for $5 \mathrm{~min}$, and then discard the supernatant. Finally, $500 \mu \mathrm{L}$ of $1 \times$ annexin V-FITC Binding Buffer was added to resuspend the pellet, and then $5 \mu \mathrm{l}$ of annexin V-FITC and $5 \mu \mathrm{L}$ of 7 -AAD were added to the cells. The samples were gently vortexed and incubated $15 \mathrm{~min}$ at $4{ }^{\circ} \mathrm{C}$ in the dark. The Flow cytometric analysis was performed by FAC-Scan cytometry (BD Biosciences, San Jose, CA). 


\section{Nuclear morphology assay and immunofluorescence assay}

Nuclear morphology was detected by Hoechst staining. Immunofluorescence study was detected by apoptosis-inducing factor (AIF) primary antibodies. The HOS, U2OS, and A2058 cells were cultured with $10 \%$ FBS on coverslips placed in six-well plates for overnight. After attachment, the cells were changed into $2 \%$ FBS media and then treated with $10-20 \mu \mathrm{M}$ of CUR, DMC and BDMC. After treatment with CUR, DMC and BDMC for 24h, HOS, U2OS, and A2058 cells were washed with phosphate buffered saline (PBS), and then fixed with $4 \%$ formaldehyde in PBS for $30 \mathrm{~min}$ at room temperature. Finally, HOS cells were added apoptosis-inducing factor (AIF) primary antibodies at $4{ }^{\circ} \mathrm{C}$ overnight, followed with the fluorescein isothiocyanate-conjugated secondary antibodies for $1 \mathrm{~h}$, and then were added $4 \mathrm{mg} / \mathrm{mL}$ Hoechst 33258 for $30 \mathrm{~min}$, but U2OS, and A2058 cells were only added $4 \mathrm{mg} / \mathrm{mL}$ Hoechst 33258 for $30 \mathrm{~min}$. The coverslips were mounted in Vectashield mounting medium and the nuclear morphology and AIF nuclear translocation were viewed under confocal laser scanning microscopy.

\section{Western blot analysis}

HOS cells with or without 10-20 $\mathrm{MM}$ CUR, DMC and BDMC treatment for $24 \mathrm{~h}$ were washed with PBS and lysed in the Golden lysis buffer containing protease inhibitors for $30 \mathrm{~min}$ at $4{ }^{\circ} \mathrm{C}$. Protein content was determined against a standardized control, using the Bio-Rad protein assay kit (Bio-Rad Laboratories). The protein inputs in the western blot analyses were normalized by loading equal amounts of total protein lysates into the SDS-PAGE gel. Transferred onto polyvinylidene difluoride membranes, and then probed with primary antibody ( $\beta$-actin, p-p38, p-Akt, p-Erk, p-Smad2, p-Smad3, cleaved PARP, or cleaved caspase 3 ) followed by secondary antibody conjugated with horseradish peroxidase. Reactive bands were visualized with enhanced chemiluminescence (ECL) reagents.

\section{Colony formation assay (Clonogenic assay)}

Cell proliferation was monitored using a colony formation assay. Briefly, HOS cells were seeded into 24-well plates with $10 \%$ FBS overnight. After attachment, cells were maintained in DMEM containing 10\% FBS with or without various concentrations of CUR, DMC and BDMC for an additional 14 days. At last, the cells were fixed with $4 \%$ paraformaldehyde for $15 \mathrm{~min}$ at room temperature and stained with crystal violet dye for 5 $\min$.

\section{Statistical analysis}

All values were expressed as mean $\pm \mathrm{SD}$. Each value is the mean of at least three separate experiments in each group. Student's t-test was used for statistical comparison. ${ }^{*}$ indicates that the values are significantly different

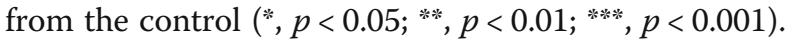

\section{Results}

CUR, DMC and BDMC inhibited the cell viability of HOS, U2OS, MDA-MB-231, and A2058 cells

To evaluate the growth inhibitory effects of CUR, DMC and BDMC (Fig. 1) on osteosarcoma (HOS and U2OS), breast (MDA-MB-231), and melanoma (A2058) cancer cells, we employed the MTT assay. Treatment with $5-25 \mu \mathrm{M}$ of CUR, DMC and BDMC for $24-48 \mathrm{~h}$ significantly resulted in inhibition of the HOS, U2OS, MDA-MB-231, and A2058 cell viability in a time- and concentration-dependent manner, but to varying extents (Fig. $2 \mathrm{a}$ and b). Osteosarcoma (HOS and U2OS) cells were more sensitive to CUR, DMC and BDMC than breast (MDA-MB-231) and melanoma (A2058) cancer cells. Thus, the HOS and U2OS cell lines were selected for further analysis. Treatment of CUR, DMC and BDMC for 24-48 h at

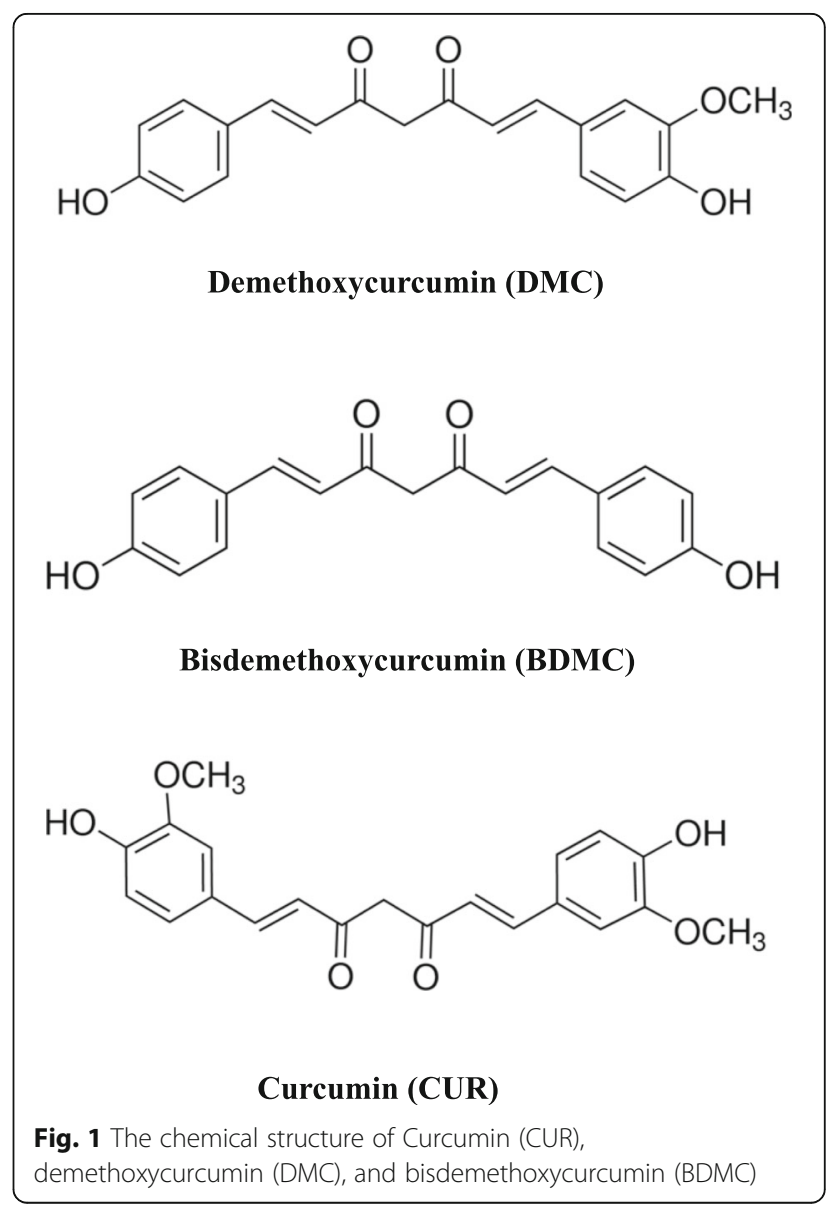



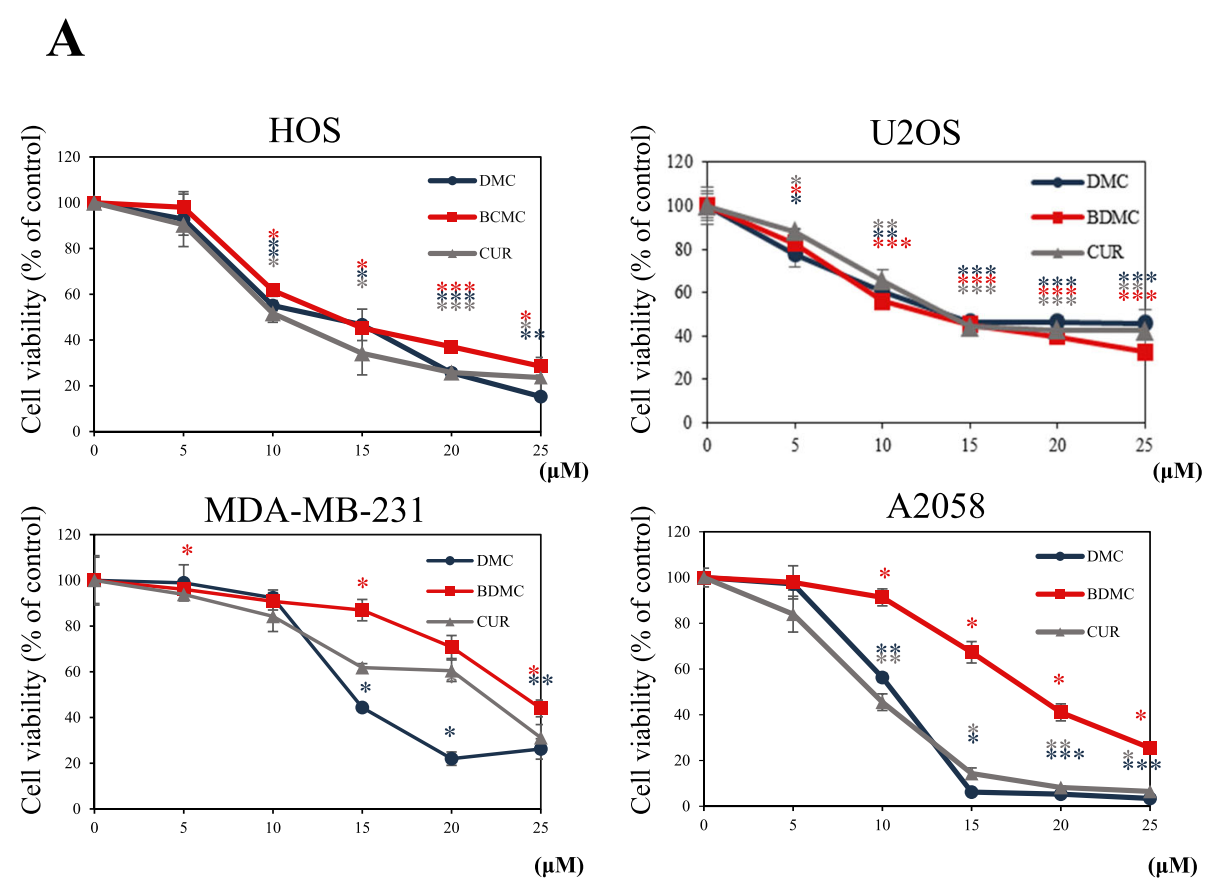

\section{B}
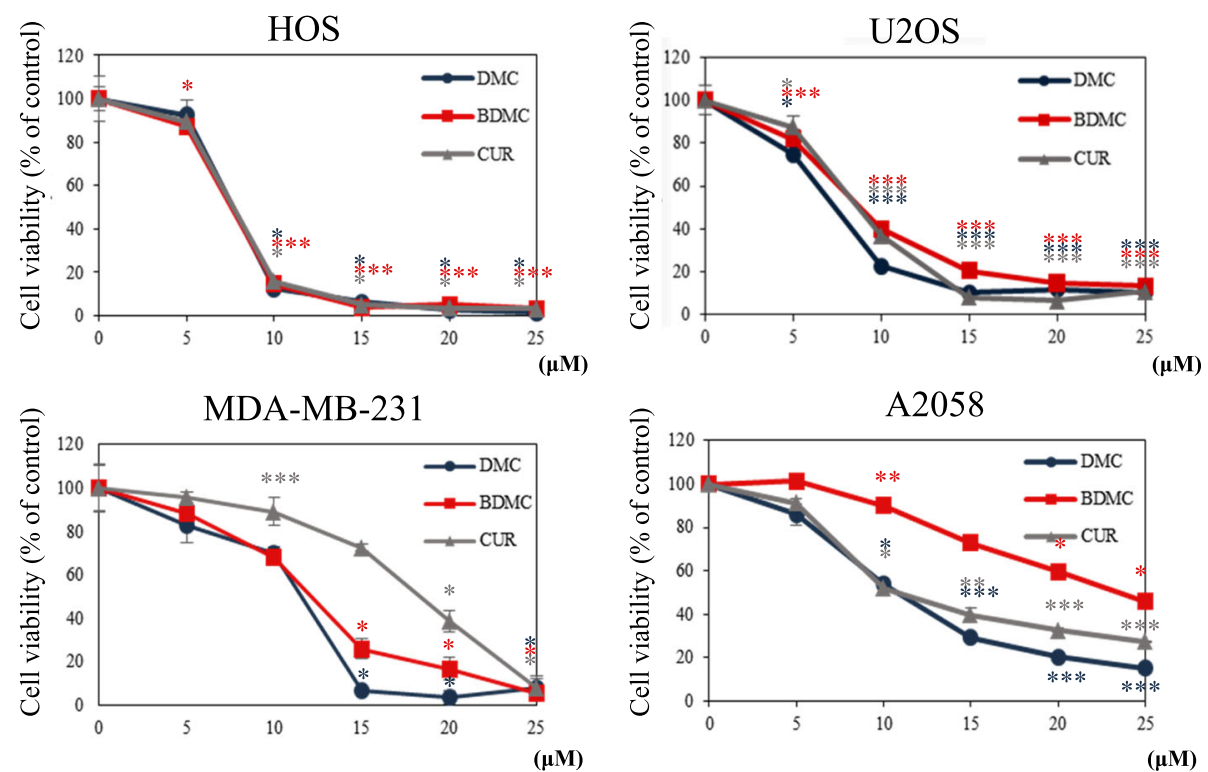

Fig. 2 Effect of cell viability of CUR, DMC, and BDMC in HOS, U2OS, MDA-MB-231, and A2058 cancer cells. The cells were treated with 5-25 $\mu M$ CUR, DMC and BDMC for (a) 24 and (b) 48 h, and cell viability was measured by the MTT assay. The percentage of cell viability was calculated as the ratio: 100\% x (A540 absorbance of the drug-treated wells / (A540 absorbance of the no drug-treated wells). ${ }^{*}$ Indicates the values are significantly different than the control $\left.{ }^{*} P<0.05,{ }^{* *} P<0.01,{ }^{* *} P<0.001\right)$

the same concentration had the same inhibiting effect on HOS and U2OS cells. However, treatment of CUR and $\mathrm{DMC}$ for $48 \mathrm{~h}$ were more active than BDMC in inhibiting A2058 cell growth. Treatment of BDMC and DMC for $48 \mathrm{~h}$ were more active than CUR in inhibiting MDA-MB-231 cell growth.
CUR, DMC and BDMC induced apoptosis in HOS cells To identify whether CUR, DMC and BDMC could increase apoptosis in HOS cells, we used the annexin V-FITC and 7-ADD double staining assay. Cells were treated with CUR, DMC and BDMC $(20 \mu \mathrm{M})$ for $24 \mathrm{~h}$, and stained with annexin V-FITC /7-AAD, and 
analyzed by flow cytometry. Early apoptotic cells were positive for annexin $\mathrm{V}$ staining and negative for 7ADD staining, necrotic cells were for negative annexin $\mathrm{V}$ staining and positive for 7-ADD staining, whereas late apoptotic cells were positive for both annexin V-FITC and 7-ADD staining. The percentage of early apoptotic cells increased from 5.6 to $60.5 \%$, 48.7 and $55.6 \%$ after treatment with CUR, DMC and BDMC for $24 \mathrm{~h}$, respectively. The percentage of necrotic cells increased from 1.7 to $0.8 \%, 0.4$ and $5.9 \%$ after treatment with CUR, DMC and BDMC for $24 \mathrm{~h}$, respectively. The percentage of late apoptotic cells were increased from 5.7 to $36.9 \%, 50.1$ and $21.1 \%$ after treatment with CUR, DMC and BDMC, respectively (Fig. 3a and b). Thus, CUR, DMC and BDMC significantly increased apoptosis (including early and late apoptosis) in HOS cells. Typical morphological characteristics of apoptotic cells could be observed through using fluorescence microscopy by nuclear staining with Hoechst 33342. Next, we would provide direct evidence of CUR, DMC and BDMC -induced apoptosis in HOS, U2OS, and A2058 cells by using Hoechst day to observe the nuclear morphology. As shown in Fig. 4a, b and c, we observed increased numbers of apoptotic cells in HOS, U2OS, and A2058 cells treated with CUR, DMC and BDMC for $24 \mathrm{~h}$. AIF nuclear translocation was a critical mediator of caspase-independent cell death. To determine whether the CUR, DMC and BDMC $(10-20 \mu \mathrm{M})$ induced caspase-independent cell death, the localization of AIF in HOS cells was observed using immunofluorescence staining experiments. As shown in Fig. 4a and b, AIF nuclear translocation was significantly increased in HOS cells treated with $10-20 \mu \mathrm{M}$ CUR, $\mathrm{DMC}$ and BDMC for $24 \mathrm{~h}$.

\section{CUR, DMC and BDMC induced caspase 3 and PARP activation and increased Smad2/3 phosphorylation in HOS cells}

In order to identify the molecular mechanism for CUR, DMC and BDMC -induced apoptosis, western blot analysis was carried out to profile the expression levels of caspase 3, PARP, p-Akt, p-p38, p-Erk 1/2, p-Smad2 and p-Smad3 in HOS cells treated with CUR, DMC and BDMC. The PARP cleavage has long been considered as a b typical biochemical hallmark of apoptosis. PARP was cleaved by caspase 3 during apoptosis in human osteosarcoma cells. The level of cleaved PARP and cleaved caspase 3 were increased on higher-dose $(20 \mu \mathrm{M})$ CUR, DMC and BDMC treatment in HOS cells, but low dose $(10 \mu \mathrm{M})$ did not (Fig. 5a). Additionally, the Smad, Akt, Erk and p38 signaling pathway also played important roles in inducing apoptosis of osteosarcoma cells. CUR, and DMC significantly induced the phosphorylation of p-Smad2 and p-Smad3 in HOS cells, but BDMC did not. BDMC decreased the phosphorylation of Akt in HOS cells, but it did not affect the phosphorylation of ERK and p38 (Fig. 5b).

\section{CUR, DMC and BDMC combination were evaluated the anticancer activity against the HOS cells}

The anticancer effects of CUR, DMC and BDMC combination on HOS cells were evaluated using the MTT test of cell viability, flow cytometric analysis of cellular DNA content, and colony formation analysis of cell proliferation. First, the combination of three compounds (CUR, DMC and BDMC) reduced cell viability better than either two or a single agent in HOS cells (Fig. 6a). The combination of the three compounds also synergistically increased apoptosis (Fig. 6b and c). Overall, the combination of the three compounds could be used as a novel target for the treatment of osteosarcoma. We next performed a colony formation assay to evaluate the effects of combinations of CUR, DMC and BDMC on HOS cell proliferation. The low dose $(10 \mu \mathrm{M})$ CUR and DMC treatment in HOS cells reduced the colony formation, but the low dose $(10 \mu \mathrm{M})$ BDMC did not. The higher dose $(20 \mu \mathrm{M})$ CUR, DMC, and DBMC significantly reduced the colony formation. The combined $10 \mu \mathrm{M}$ BDMC with $10 \mu \mathrm{M}$ CUR or DMC synergistically reduced the colony formation than single agents alone in HOS cells (Fig. 6d).

\section{Discussion}

The pharmacological activity of turmeric has been attributed mainly to the three curcuminoid constituents, including CUR, DMC and BDMC. Although CUR was well known for its anti-tumor, anti-oxidant, antiinflammatory, anti-neurotoxicity, anti-angiogenesis, anti-viral, and anti-bacterial, the ability of two related compounds DMC and BDMC in turmeric were less well known. The present study found that all three curcuminoids (CUR, DMC and BDMC) are equipotent in inducing HOS cell apoptosis by caspasedependent and -independent pathways through activation of Smad2/3 and repression of Akt signaling pathway. Furthermore, we demonstrated that the combination of the three curcuminoids synergistically increased apoptosis than either two or a single agent in HOS cells. The synergistic effects of these three curcuminoids were in agreement with the previously reported studies which indicated that the curcuminoid mixture was more active than the individual components [1].

Previous studies reported that the relative potency for decreasing of TNF- $\alpha$ induced NF- $\mathrm{kB}$ activation was Cur $>$ DMC $>$ BDMC [1]. Our findings were 
A

\section{HOS Cells (24h)}

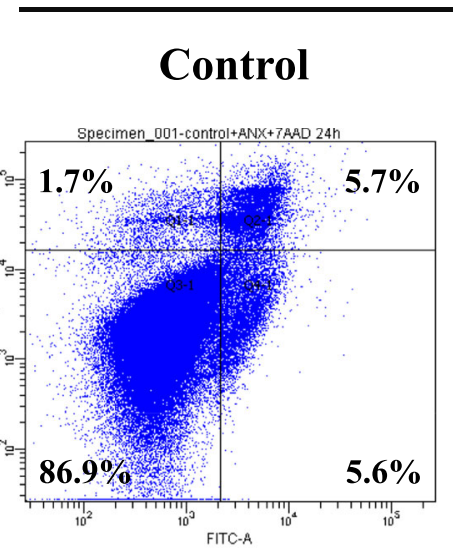

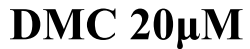

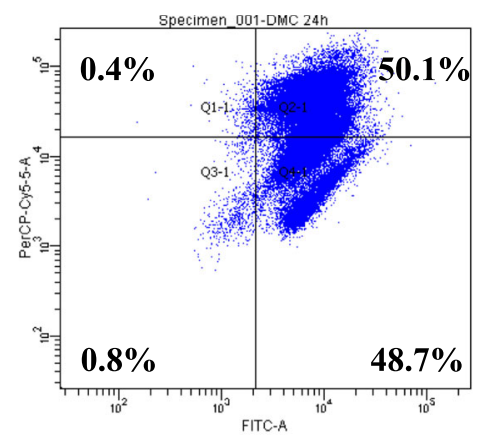

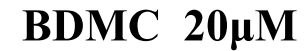

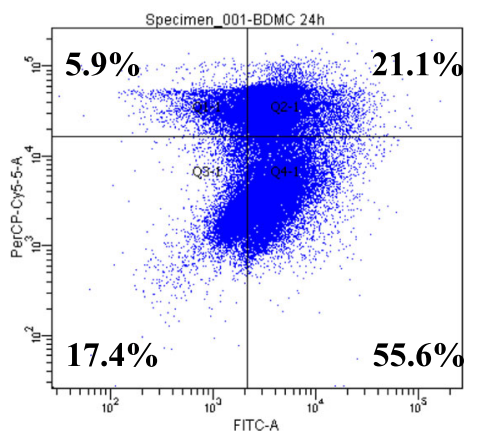

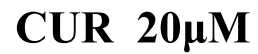

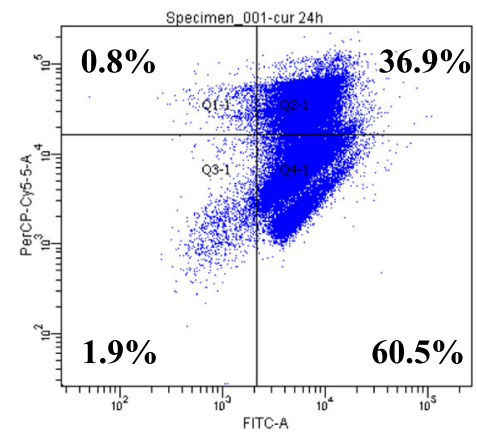

B

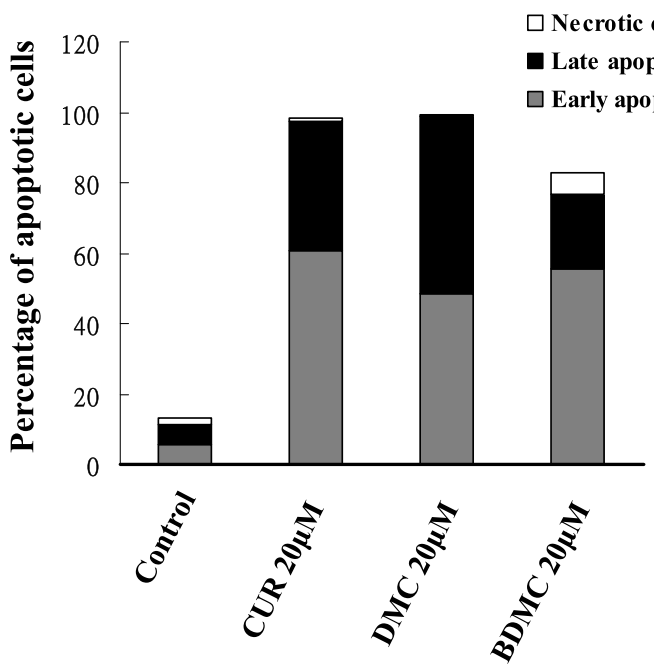

Fig. 3 Effects of CUR, DMC, and BDMC on the apoptosis of HOS cells. a HOS cells were treated with $20 \mu M$ CUR, DMC, and BDMC for $24 \mathrm{~h}$ and stained with annexin V-FITC /7-AAD, and analyzed by flow cytometry. $\mathbf{b}$ Quantitative analysis of the percentage of early apoptotic and late apoptotic cells in HOS cells 


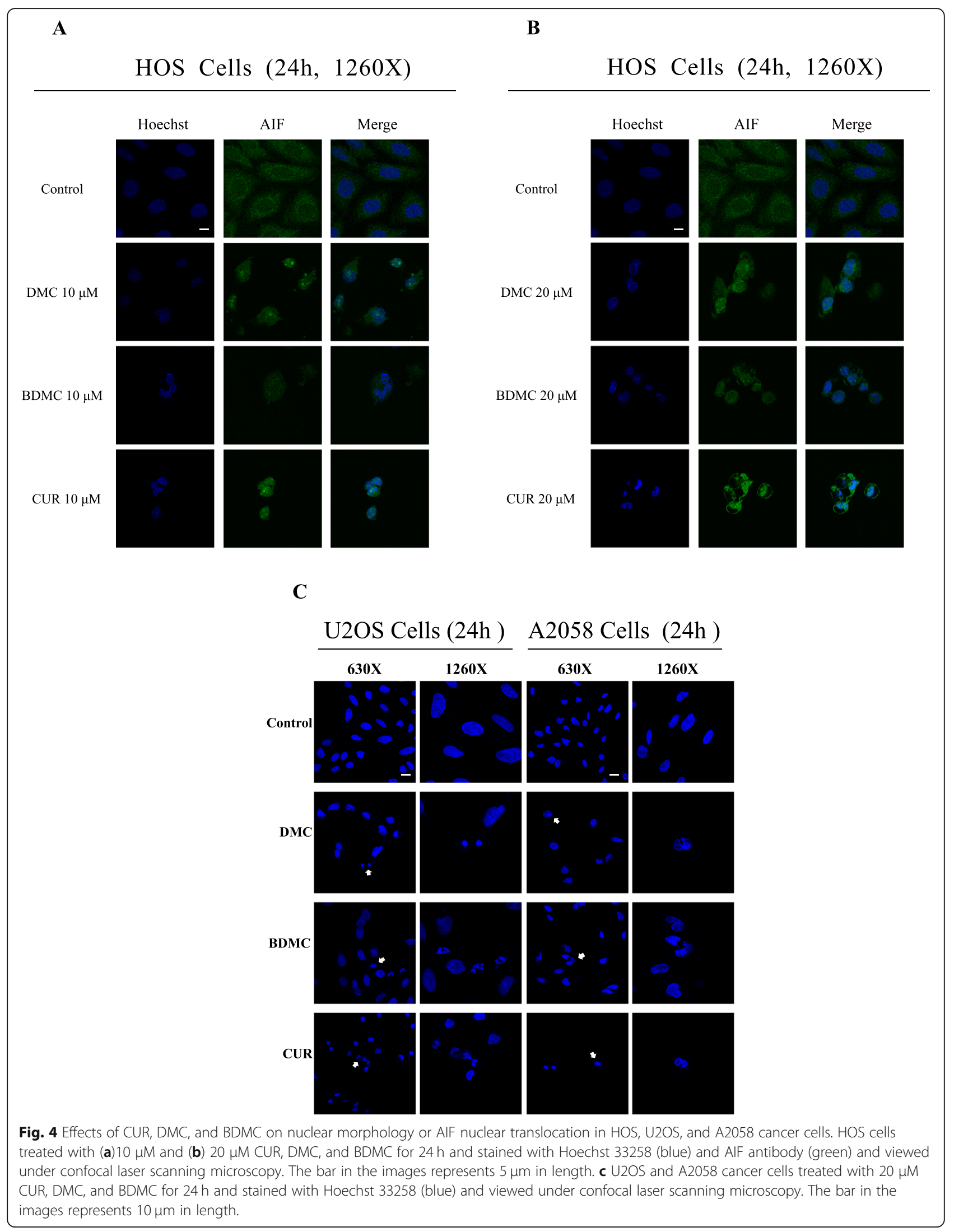


A

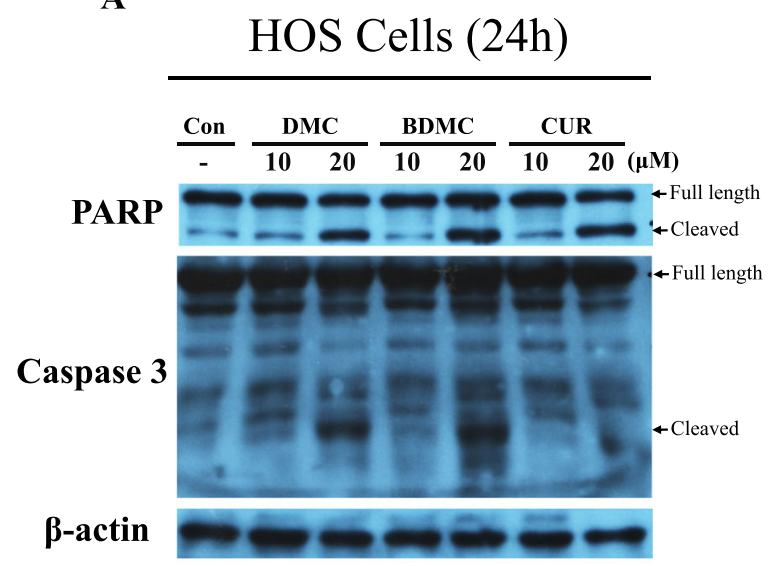

B

HOS Cells

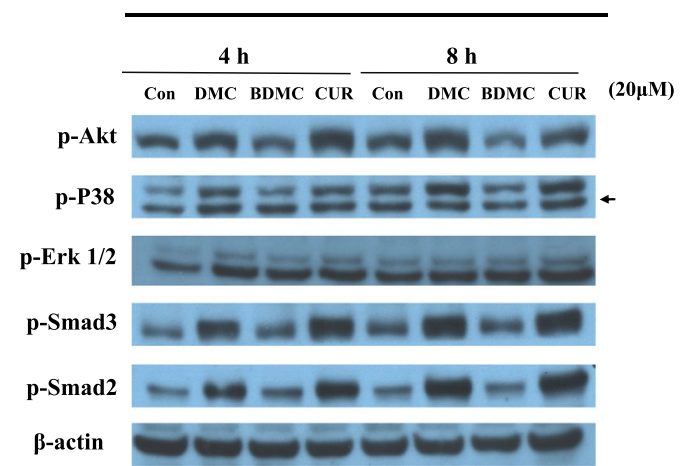

Fig. 5 a The expression of full length caspase-3, cleaved caspase-3, full length PARP and cleaved PARP in HOS cells treated with 10-20 $\mu M$ CUR, DMC, and BDMC for $24 \mathrm{~h}$ were detected using the western blotting assay. b Expression of p-Akt, p-p38, p-Erk 1/2, p-Smad2 and p-Smad 3 in HOS cells treated with $20 \mu \mathrm{M}$ CUR, DMC, and BDMC for 4-8 $\mathrm{h}$ was detected using the western blotting assay

similar to previous study. Cur and DMC reduced cell viability better than BDMC in MDA-MB-231 and A2058 cancer cells. BDMC was chemically more stable than CUR and DMC, but its anti-breast cancer or anti-melanoma effects were lower than CUR and DMC. However, equimolar concentrations of CUR, DMC and BDMC had the same inhibitory effect on HOS and U2OS cells. CUR and DMC contain either two or one phenyl methoxy groups, whereas BDMC contains none. These results suggested that the methoxy groups on the phenyl ring played a more important role in the prevention of breast and melanoma cancer in comparison to osteosarcoma. While it is unclear why the different cell lines exhibited distinct sensitivity to suppression of cellular proliferation after CUR, DMC, or BDMC treatment.

Many research had shown that three curcuminoids (CUR, DMC and BDMC) are hypomethylation agent to suppress DNA methyltransferases (DnMT) activity in non-small cell lung cancer cell lines [24]. BDMC exhibited much better chemical stability, demethylation effect, and anti-invasion ability [14] than CUR and DMC. In this study, CUR, DMC and BDMC have the same inhibitory effect on HOS and U2OS cells under the same concentrations. Surprisingly, we observed that CUR and DMC induced the apoptosis of HOS cells through activating of Smad2/3 signaling pathway, but BDMC did not. A recent study has found that the overexpression of $\mathrm{p}-\mathrm{Smad} 2, \mathrm{p}-\mathrm{Smad} 3$, and Smad4 increased caspase 3 and caspase 9 activation in osteosarcoma cells [25]. Notably, we found that CUR, and DMC significantly induced caspase 3 activation and $\mathrm{p}-\mathrm{Smad} 2 / 3$ phosphorylation in HOS cells. These results suggested that CUR, and DMC induced caspase-mediated apoptosis in HOS cells through the Smad signaling pathways. Additionally, the low expression of inhibitor of growth family member 5 (ING5) which was a tumor suppressor gene was detectable in HOS cells. Overexpression of ING5 in HOS cells induced apoptosis by activating the Smad2/3 and caspase 3/9 [25]. Thus, whether CUR and DMC also could regulate ING5 protein expression remain to be investigated. However, BDMC induced caspase-mediated apoptosis in HOS cells through the Akt signaling pathways. Activation of Smad2/3 or inhibition of Akt may represent a promising approach for the targeted therapy for osteosarcoma. Because many signaling pathways played vital roles in the development of cancer, using targeted agents to inhibit multiple signaling pathways are frequently deregulated in cancers [26-28]. This suggested that collective action rather than just a single effect became more important for anticancer therapy. Thus, synergistic induction of apoptosis by combination treatment with these three compounds might regulate multiple signaling pathways in osteosarcoma. Further study will be required to investigate the molecular mechanisms of combined CUR, DMC and BDMC and evaluate the anticancer effects of three compounds on murine xenograft models of human osteosarcoma cell lines. Overall, these findings provide novel insight into the combination of these three compounds.

\section{Conclusions}

In the present study, CUR,DMC, and BDMC all decreased cell viability in osteosarcoma (HOS and U2OS), breast (MDA-MB-231), and melanoma (A2058). Additionally, CUR,DMC, and BDMC all decreased cell viability and induced the apoptosis of HOS cells through activation of Smad $2 / 3$ and 


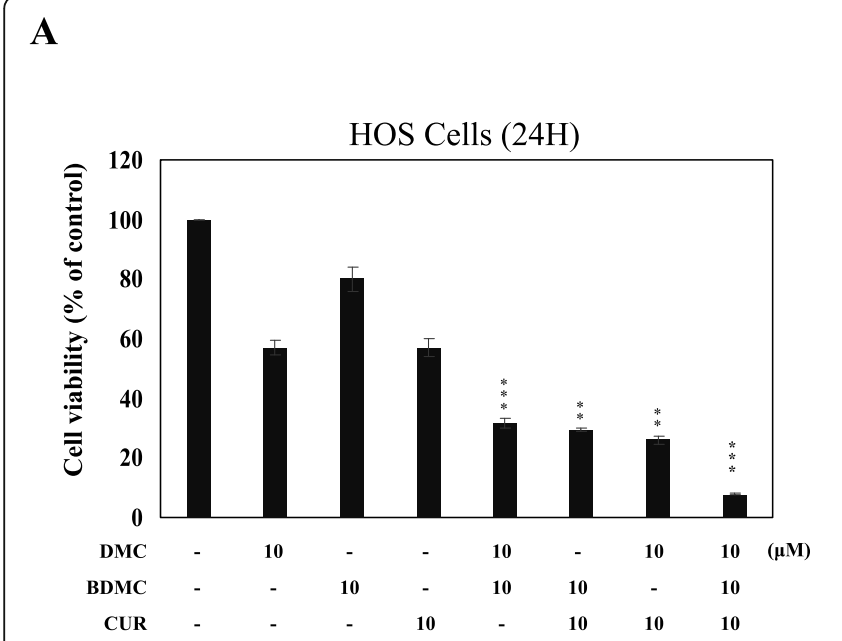

B

HOS Cells (24h)
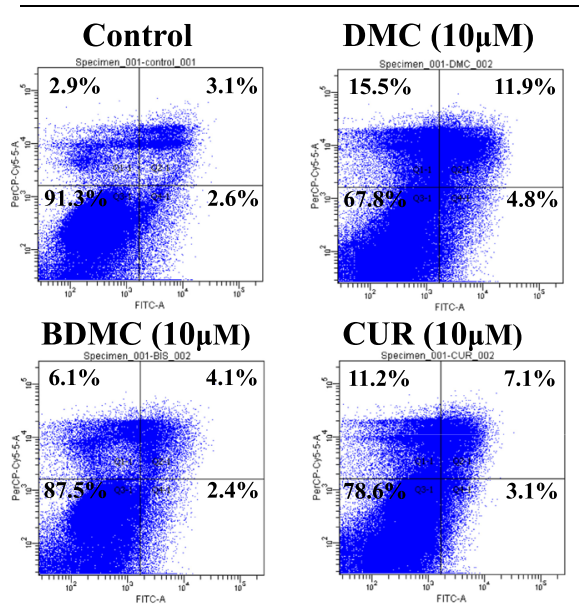

DMC + BDMC
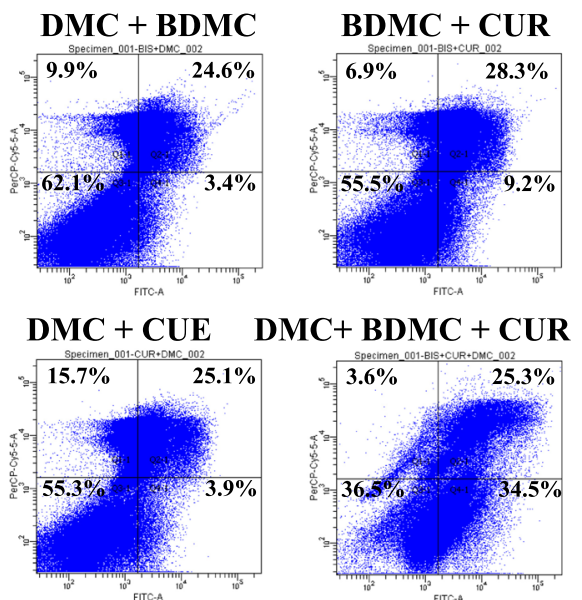

C

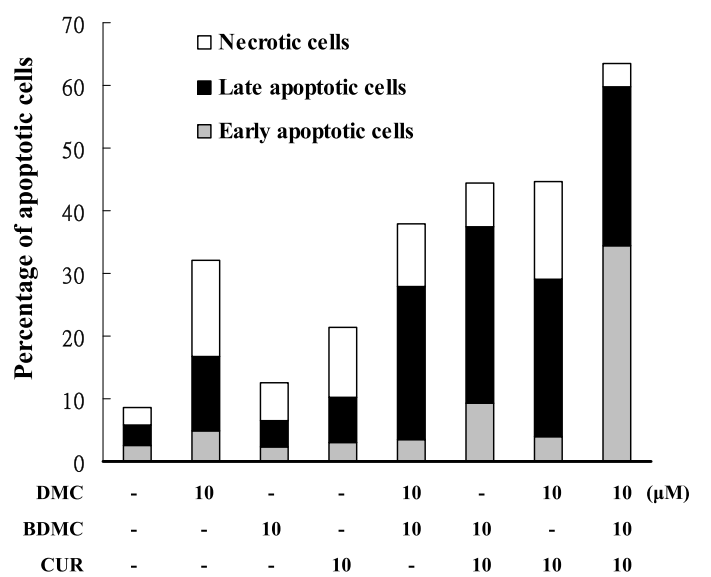

D HOS Cells (24h)

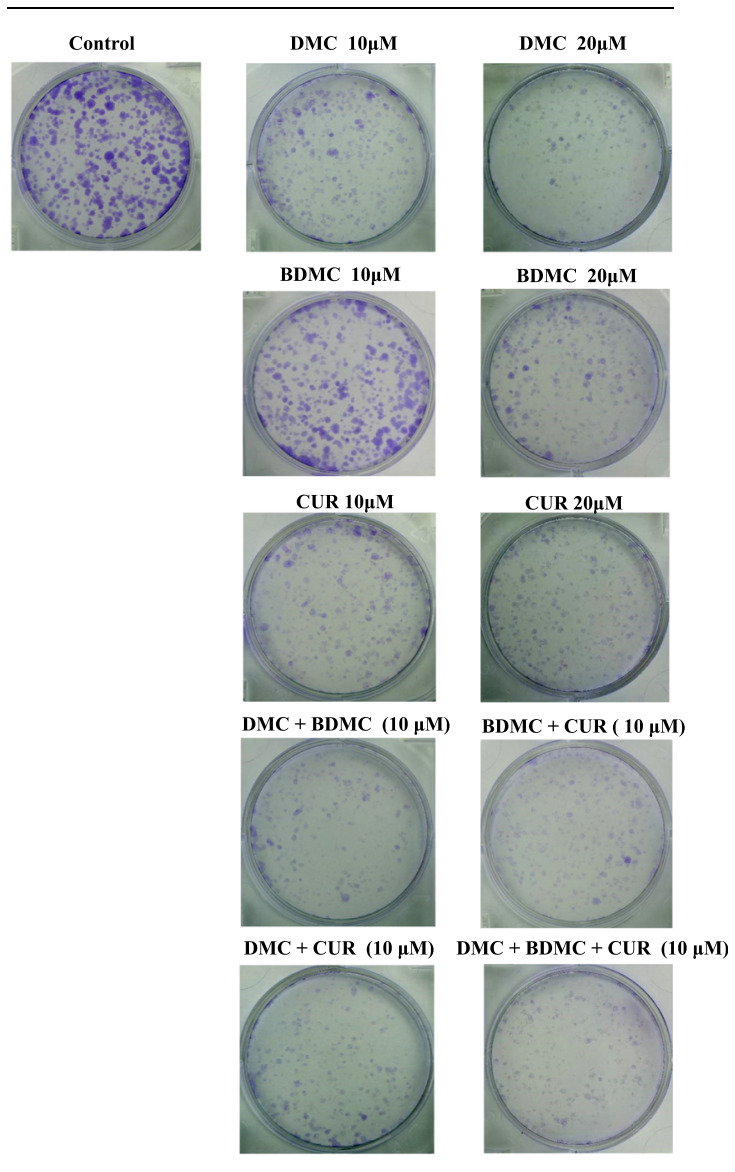

Fig. 6 The combined effects of CUR, DMC, and BDMC on cell viability (a), apoptosis (b), and colony formation (d) in HOS cells. HOS cells treated with $10 \mu \mathrm{M}$ CUR, DMC, and BDMC or their combination as indicated in the figure for $24 \mathrm{~h}$ were detected using MTT assay, annexin V-FITC /7-AAD staining, and clonogenic assay. c Quantitative analysis of the percentage of early apoptotic and late apoptotic cells in HOS cells. The percentage of cell viability was calculated as the ratio: 100\% x (A540 absorbance of the drug-treated wells / (A540 absorbance of the no drug-treated wells). * Indicates the values are significantly different than the control $\left({ }^{*} P<0.05,{ }^{* *} P<0.01,{ }^{* * *} P<0.001\right.$ ) 
repression of Akt signaling pathway. Furthermore, we also want to examine the combined effects of CUR, DMC and BDMC on HOS cell proliferation. The combination of CUR,DMC, and BDMC synergistically reduced the cell viability, colony formation and increased apoptosis than either two or a single agent in HOS cells. Overall, the combination of these three compounds could be used as a novel target for the treatment of osteosarcoma.

\section{Supplementary information}

Supplementary information accompanies this paper at https://doi.org/10. 1186/s12906-020-2857-1.

\section{Additional file 1.}

\section{Abbreviations}

AIF: Apoptosis-inducing factor; BCRC: Bioresource Collection and Research Center; BDMC: Bisdemethoxycurcumin; CUR: Curcumin; DMC: Demethoxycurcumin; DMEM: Dulbecco's Modified Eagle's Medium; ECL: Chemiluminescence; ING5: Inhibitor of growth family member; PBS: Phosphate buffered saline

\section{Acknowledgements}

Not applicable.

\section{Authors' contributions}

$\mathrm{CH}, \mathrm{HFL}$ and $\mathrm{YHC}$, carried out the experiments. JCH and WHC analyzed the data. $\mathrm{HCH}$ wrote the paper. All authors read and approved the final manuscript.

\section{Funding}

This work was supported by grants from the National Science Council, Taiwan (MOST 107-2320-B-007-001 and MOST 108-2320-B-007 -006 -MY3).

\section{Availability of data and materials}

The datasets used and/or analysed during the current study are available from the corresponding author on reasonable request.

\section{Ethics approval and consent to participate}

Not applicable.

\section{Consent for publication}

Not applicable.

\section{Competing interests}

The authors declare that they have no competing interests.

\section{Author details}

'Department of Biotechnology and Laboratory Science in Medicine, National Yang-Ming University, Taipei 11221, Taiwan. ${ }^{2}$ Department of Earth and Life Sciences, University of Taipei, Taipei 11153 , Taiwan. ${ }^{3}$ Departments of Clinical Pathology, Cheng Hsin General Hospital, Taipei 11221, Taiwan. ${ }^{4}$ Department of Restaurant, Hotel and Institutional Management, Fu-Jen Catholic University, New Taipei 24205, Taiwan. ${ }^{5}$ Department of Applied Science, National Tsing Hua University South Campus, No.521, Nanda Rd, Hsinchu City 30014, Taiwan. ${ }^{6}$ Department of Biochemical Science and Technology, National Chiayi University, Chiayi 60004, Taiwan. ${ }^{7}$ School of Medicine, National Defense Medical Center, Taipei 11490, Taiwan. ${ }^{8}$ Department of Orthopedics, Cheng Hsin General Hospital, Taipei 11220, Taiwan.

Received: 5 November 2019 Accepted: 20 February 2020

Published online: 03 March 2020

\section{References}

1. Sandur SK, Pandey MK, Sung B, Ahn KS, Murakami A, Sethi G, Limtrakul P, Badmaev V, Aggarwal BB. Curcumin, demethoxycurcumin, bisdemethoxycurcumin, tetrahydrocurcumin and turmerones differentially regulate anti-inflammatory and anti-proliferative responses through a ROSindependent mechanism. Carcinogenesis. 2007;28(8):1765-73.

2. Amalraj A, Pius A, Gopi S, Gopi S. Biological activities of curcuminoids, other biomolecules from turmeric and their derivatives - a review. J Tradit Complement Med. 2017;7(2):205-33.

3. Barati N, Momtazi-Borojeni AA, Majeed M, Sahebkar A. Potential therapeutic effects of curcumin in gastric cancer. J Cell Physiol. 2019;234(3):2317-28.

4. Batra H, Pawar S, Bahl D. Curcumin in combination with anti-cancer drugs: a nanomedicine review. Pharmacol Res. 2019;139:91-105.

5. Khorsandi K, Hosseinzadeh R, Shahidi FK. Photodynamic treatment with anionic nanoclays containing curcumin on human triple-negative breast cancer cells: cellular and biochemical studies. J Cell Biochem. 2019;120(4): 4998-5009.

6. Willenbacher E, Khan SZ, Mujica SCA, Trapani D, Hussain S, Wolf D, Willenbacher W, Spizzo G, Seeber A. Curcumin: New Insights into an Ancient Ingredient against Cancer. Int J Mol Sci. 2019;20(8):1808.

7. Xia M, Ye Z, Shi Y, Zhou L, Hua Y. Curcumin improves diabetes mellitusassociated cerebral infarction by increasing the expression of GLUT1 and GLUT3. Mol Med Rep. 2018;17(1):1963-9.

8. Pivari F, Mingione A, Brasacchio C, Soldati L. Curcumin and Type 2 Diabetes Mellitus: Prevention and Treatment. Nutrients. 2019;11(8):1837.

9. Ghosh S, Banerjee S, Sil PC. The beneficial role of curcumin on inflammation, diabetes and neurodegenerative disease: a recent update. Food Chem Toxicol. 2015;83:111-24.

10. Randino R, Grimaldi M, Persico M, De Santis A, Cini E, Cabri W, Riva A, D'Errico G, Fattorusso C, D'Ursi AM, et al. Investigating the Neuroprotective effects of turmeric extract: structural interactions of beta-amyloid peptide with single Curcuminoids. Sci Rep. 2016;6:38846.

11. Paolino D, Vero A, Cosco D, Pecora TM, Cianciolo S, Fresta M, Pignatello R. Improvement of Oral bioavailability of Curcumin upon microencapsulation with Methacrylic copolymers. Front Pharmacol. 2016;7:485.

12. Jeengar MK, Shrivastava S, Nair K, Singareddy SR, Putcha UK, Talluri MV, Naidu VG, Sistla R. Improvement of bioavailability and anti-inflammatory potential of curcumin in combination with emu oil. Inflammation. 2014; 37(6):2139-55.

13. Ahmad N, Umar S, Ashafaq M, Akhtar M, lqbal Z, Samim M, Ahmad FJ. A comparative study of PNIPAM nanoparticles of curcumin, demethoxycurcumin, and bisdemethoxycurcumin and their effects on oxidative stress markers in experimental stroke. Protoplasma. 2013;250(6): 1327-38.

14. Yodkeeree S, Chaiwangyen W, Garbisa S, Limtrakul P. Curcumin, demethoxycurcumin and bisdemethoxycurcumin differentially inhibit cancer cell invasion through the down-regulation of MMPs and UPA. J Nutr Biochem. 2009;20(2):87-95.

15. Eftekhari F. Imaging assessment of osteosarcoma in childhood and adolescence: diagnosis, staging, and evaluating response to chemotherapy. Cancer Treat Res. 2009;152:33-62

16. Misaghi A, Goldin A, Awad M, Kulidjian AA. Osteosarcoma: a comprehensive review. SICOT J. 2018;4:12.

17. Suresh S, Saifuddin A. Radiological appearances of appendicular osteosarcoma: a comprehensive pictorial review. Clin Radiol. 2007;62(4):314-23.

18. Ang LF, Yam MF, Fung YT, Kiang PK, Darwin Y. HPLC method for simultaneous quantitative detection of quercetin and curcuminoids in traditional chinese medicines. Aust J Pharm. 2014;17(4):36-49.

19. Anderson PM. Effectiveness of radiotherapy for osteosarcoma that responds to chemotherapy. Mayo Clin Proc. 2003;78(2):145-6.

20. Lewis VO, Raymond K, Mirza AN, Lin P, Yasko AW. Outcome of postradiation osteosarcoma does not correlate with chemotherapy response. Clin Orthop Relat Res. 2006;450:60-6.

21. Gota VS, Maru GB, Soni TG, Gandhi TR, Kochar N, Agarwal MG. Safety and pharmacokinetics of a solid lipid curcumin particle formulation in osteosarcoma patients and healthy volunteers. J Agric Food Chem. 2010; 58(4):2095-9.

22. Akiyama T, Dass CR, Choong PF. Novel therapeutic strategy for osteosarcoma targeting osteoclast differentiation, bone-resorbing activity, and apoptosis pathway. Mol Cancer Ther. 2008;7(11):3461-9.

23. Lee DS, Lee MK, Kim JH. Curcumin induces cell cycle arrest and apoptosis in human osteosarcoma (HOS) cells. Anticancer Res. 2009;29(12):5039-44.

24. Liu YL, Yang HP, Gong L, Tang CL, Wang HJ. Hypomethylation effects of curcumin, demethoxycurcumin and bisdemethoxycurcumin on WIF-1 
promoter in non-small cell lung cancer cell lines. Mol Med Rep. 2011;4(4): 675-9.

25. Zhang $X, X u Z H, X i e ~ H$, Sun YW, Liu J, Zhao YB. ING5 is a potential target for osteosarcoma therapy. Technol Cancer Res Treat. 2018;17:1-5.

26. Unger FT, Witte I, David KA. Prediction of individual response to anticancer therapy: historical and future perspectives. Cell Mol Life Sci. 2015;72(4):72957.

27. Khan M, Maryam A, Qazi Jl, Ma T. Targeting apoptosis and multiple signaling pathways with Icariside II in Cancer cells. Int J Biol Sci. 2015;11(9): 1100-12.

28. Farha AK, Dhanya SR, Mangalam SN, Geetha BS, Latha PG, Remani P. Deoxyelephantopin impairs growth of cervical carcinoma SiHa cells and induces apoptosis by targeting multiple molecular signaling pathways. Cell Biol Toxicol. 2014;30(6):331-43.

\section{Publisher's Note}

Springer Nature remains neutral with regard to jurisdictional claims in published maps and institutional affiliations.

Ready to submit your research? Choose BMC and benefit from:

- fast, convenient online submission

- thorough peer review by experienced researchers in your field

- rapid publication on acceptance

- support for research data, including large and complex data types

- gold Open Access which fosters wider collaboration and increased citations

- maximum visibility for your research: over $100 \mathrm{M}$ website views per year

At BMC, research is always in progress.

Learn more biomedcentral.com/submissions 